\title{
Prevalence of latent tuberculosis and treatment adherence among patients with chronic kidney disease in Campo Grande, State of Mato Grosso do Sul
}

\author{
Aucely Corrêa Fernandes Chagas ${ }^{[1]}$, Günter Hans Filho ${ }^{[1]}$,

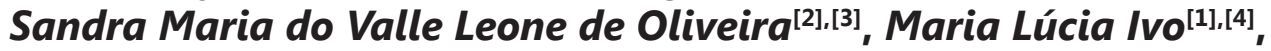 \\ Ruy Alberto Caetano Corrêa Filho ${ }^{[5]}$ and Maria Ilizabeth Donatti ${ }^{[6]}$
}

[1]. Programa de Pós-Graduação em Saúde e Desenvolvimento na Região Centro-Oeste, Universidade Federal do Mato Grosso do Sul, Campo Grande, MS. [2]. Faculdade de Medicina, Universidade Federal de Mato Grosso do Sul, Campo Grande, MS. [3]. Escritório Regional, Fundação Oswaldo Cruz, Campo Grande, MS. [4]. Programa de Pós Graduação - Mestrado em Enfermagem, Universidade Federal do Mato Grosso do Sul, Campo Grande, MS. [5]. Faculdade de Medicina Veterinária e Ciência Animal, Universidade Federal do Mato Grosso do Sul, Campo Grande, MS. [6]. Hospital Universitário Maria Aparecida Pedrossian, Universidade Federal do Mato Grosso do Sul, Campo Grande, MS

\begin{abstract}
Introduction: The primary strategy for tuberculosis control involves identifying individuals with latent tuberculosis. This study aimed to estimate the prevalence of latent tuberculosis in chronic kidney disease (CKD) patients who were undergoing hemodialysis in Campo Grande, State of Mato Grosso do Sul, Brazil, to characterize the sociodemographic and clinical profiles of patients with latent tuberculosis, to verify the association between sociodemographic and clinical characteristics and the occurrence of latent tuberculosis, and to monitor patient adherence to latent tuberculosis treatment. Methods: This epidemiological study involved 418 CKD patients who were undergoing hemodialysis and who underwent a tuberculin skin test. Results: The prevalence of latent tuberculosis was $10.3 \%$. The mean patient age was $53.43 \pm 14.97$ years, and the patients were predominantly men $(63.9 \%)$. The population was primarily Caucasian $(58.6 \%)$; half $(50 \%)$ were married, and $49.8 \%$ had incomplete primary educations. Previous contact with tuberculosis patients was reported by $80 \%$ of the participants. Treatment adherence was 97.7\%. Conclusions: We conclude that the prevalence of latent tuberculosis in our study population was low. Previous contact with patients with active tuberculosis increased the occurrence of latent infection. Although treatment adherence was high in this study, it is crucial to monitor tuberculosis treatment administered to patients in health services to maintain this high rate.
\end{abstract}

Keywords: Prevalence. Latent tuberculosis. Chronic kidney disease. Tuberculin skin test. Renal dialysis.

\section{INTRODUCTION}

Tuberculosis (TB) is a serious public health problem. It is the second most frequent cause of death from infectious disease worldwide. According to the World Health Organization ${ }^{1}$, Brazil ranks $17^{\text {th }}$ in a group of 22 countries that account for $82 \%$ of new TB cases worldwide.

In 2012, 70,047 new cases emerged in Brazil, with an incidence rate of 36.1 cases per 100,000 inhabitants. In 2011, 4,563 deaths from TB occurred, resulting in a mortality rate of 2.4 deaths per 100,000 individuals. The cases were concentrated in 315 of the 5,564 municipalities in the country; these 315 municipalities accounted for $70 \%$ of all cases $^{2}$. The disease often affects people of reproductive age and frequently leads

\footnotetext{
Address to: $\mathrm{Dr}^{\mathrm{a}}$ Aucely Corrêa Fernandes Chagas. Rua Roney Paini Malheiros 145, Casa 31, Bairro Coophamat, 79092-220 Campo Grande, MS, Brasil. Phone: $55678114-6605$

e-mail: aucelychagas@hotmail.com

Received 12 February 2014

Accepted 11 April 2014
}

to hospitalization, thus significantly increasing National Health Service $\operatorname{costs}^{3,4}$.

In 2012, the incidence of TB in the State of Mato Grosso do Sul was 37.7 cases per 100,000 inhabitants and resulted in 65 deaths ${ }^{2}$. In the capital, Campo Grande, 316 cases were reported; however, latent infection with Mycobacterium tuberculosis was not documented ${ }^{5}$. Therefore, one of the aims of this study was to investigate the prevalence of latent tuberculosis (LTB) in patients with chronic kidney disease (CKD), the $12^{\text {th }}$ and $17^{\text {th }}$ leading causes of death and disability worldwide, respectively ${ }^{3,4}$.

The morbidity and mortality rates of TB are high, particularly in patients of reproductive age, which results in increased treatment costs for CKD patients and renders TB a serious public health problem ${ }^{6-8}$.

According to the 2011 Brazilian dialysis census report, the estimated number of patients participating in a chronic dialysis program in Brazil exceeded 91,314. The cost of the dialysis program combined with renal transplants in Brazil is approximately 1.4 billion reals per year 9

Tuberculosis diagnosis in dialysis patients can be complicated and difficult because of the increased frequency of extrapulmonary involvement, which may result in atypical clinical manifestations 
and nonspecific symptoms ${ }^{10}$. Extrapulmonary TB was more commonly identified than pulmonary $\mathrm{TB}$, with tuberculous lymphadenitis being the most frequent form ${ }^{11}$.

Latent tuberculosis was characterized by the presence of bacilli in host tissues without clinical or radiological evidence of disease ${ }^{12}$. LTB affects approximately one-third of the world's population. It is estimated that 50 million Brazilians are infected with $M$. tuberculosis. Approximately $5 \%$ of the individuals carrying the tuberculosis bacillus will develop the active form of the disease, and $95 \%$ will present with LTB $^{12}$.

The tuberculin skin test (TST) is widely used to detect individuals with latent infection ${ }^{13}$. However, some TST limitations have been reported, including anergy as a consequence of chronic impaired renal immunity, possible false-negative results, and low test sensitivity ${ }^{14,15}$.

Impaired immunity in people with CKD is the main risk factor for the development of TB. In recent years, the incidence rate of TB has been increasing in this population because of immunosuppression, particularly in individuals who have undergone renal transplantation.

Immune system weakness in CKD occurs as a result of chronic inflammatory conditions, renal replacement therapies, and chronic renal failure or other comorbidities ${ }^{15}$. Moreover, nutritional status, vitamin D deficiency, and hyperparathyroidism contribute to impaired immunity in CKD patients ${ }^{16}$.

An increased risk for TB in dialysis patients was first reported by Pradhan et al. ${ }^{17}$ in 1974. Decades later, another study showed a significantly increased risk of TB in patients with chronic renal failure who were undergoing dialysis ${ }^{18}$. In cohort studies, the relative risk of TB among such patients was 3.4 to 25.3 times greater than that among the general population ${ }^{19-22}$.

Tuberculosis is the second leading cause of death from infectious disease, and its control is one of the millennium development goals, which aim to halve the numbers of cases and deaths from TB by $2015^{23}$. Therefore, the ability to identify individuals at increased risk for developing TB has important implications for public health policy and patient care ${ }^{24}$.

Considering this goal, the aims of this study were to estimate the prevalence of LTB in CKD patients who were undergoing hemodialysis, to characterize the sociodemographic and clinical profiles of patients with latent tuberculosis, to verify the association between sociodemographic and clinical characteristics and the occurrence of latent tuberculosis, and to monitor the treatment adherence of LTB patients in Campo Grande, State of Mato Grosso do Sul (MS), Brazil.

\section{METHODS}

In this epidemiological study, we conducted a descriptive survey of the six existing dialysis services in Campo Grande, MS, Brazil, from July 2011 to December 2013.

A nonprobability convenience sample was used. The six dialysis centers in Campo Grande served 772 CKD patients, $418(54.1 \%)$ of whom participated in this study.
Patients older than 18 years, CKD patients, and patients undergoing hemodialysis were included in the study. Indigenous people, pregnant women, prisoners, individuals being treated for $\mathrm{TB}$, and patients who refused to sign the informed consent form were excluded.

We used a standardized sociodemographic data questionnaire (i.e., sex, age, race, education, marital status, provenance, origin, family income, and occupation prior to CKD) and gathered information concerning other variables, such as the duration of hemodialysis-associated disease, use of medication, presence of a bacillus Calmette-Guérin (BCG) vaccination scar, and history of contact with TB or an active TB patient.

The participants underwent TSTs using the Mantoux method, which consists of the application of intradermal tuberculin purified protein derivative (PPD) RT23 (State Serum Institute, Copenhagen, Denmark) in the middle third of the anterior surface of the forearm at a dose of $0.1 \mathrm{~mL}$, equivalent to 2 tuberculin units. Forty-eight hours after the application, the reading was performed by a trained professional who measured the induration at its largest transverse axis with a ruler. The result was expressed in millimeters.

In the TST, an induration cutoff value of $10 \mathrm{~mm}$ was used for patients with chronic renal failure. This value aligned with the recommendations of the Ministry of Health and III Guidelines for Tuberculosis of the Brazilian Society of Pneumology and Tisiology ${ }^{2,26}$. Patients with TST values $\geq 10 \mathrm{~mm}$ underwent chest radiography and were evaluated by a pulmonologist to exclude active disease.

All patients who were considered positive for LTB but with no radiological evidence of active TB were directed to undergo a 6-month treatment with isoniazid at the maximum allowable dose of $300 \mathrm{mg} /$ day after hemodialysis, as recommended by the Ministry of Health and III Guidelines for Tuberculosis of the Brazilian Society of Pneumology and Tisiology $y^{2,26}$.

A 95\% confidence interval (CI) for the prevalence of TB was estimated assuming a finite population size and using an F distribution ${ }^{25}$.

For statistical analysis of categorical or nominal variables, frequency distribution tables were compiled. To test the associations among categorical variables, we used Pearson's chi-squared test or, when the expected values in the tables fell below five, Fisher's exact test. All analyses were performed using the Statistical Analyses System (SAS) 9.1 program (World Headquarters, SAS Institute, USA $)^{27}$. The prevalence ratios were calculated by point and $95 \% \mathrm{CI}$, with the estimates obtained via Poisson regression, and robust variance using the GENMOD procedure in SAS.

\section{Ethical considerations}

The ethics committee of the Federal University of Mato Grosso do Sul approved this study under protocol number 2042/0138.0.049000.

\section{RESULTS}

The study sample consisted of 418 patients who voluntarily agreed to participate. The prevalence of LTB was $10.3 \%$ (95\% CI, 8.40-12.54). 
The hemodialysis services, patient population undergoing hemodialysis, sample size, and TST results that were considered positive for LTB are shown in Table 1.

Regarding their provenance, the patients were divided into two groups, namely those who came from the interior and those who came from the capital. These groups were further divided according to city region and organized into health districts. Of the study population, $81.1 \%$ came from the following districts in the capital: east, north, west, and south. In Campo Grande in 2012 (Table 2), we observed that 331 active TB cases were reported; this result was proportional to the number of LTB cases found in this study.

The mean \pm SD age of the participants was $53.43 \pm 14.97$ years. The majority of patients were male $(63.9 \%)$ and Caucasian (58.6\%). Many were married (50\%) and had incomplete primary educations (49.8\%).

The results of the evaluation of the association between the TST results and the epidemiological characteristics are described in Table 3. No significant association was found ( $p>0.05)$.

The clinical characteristics were also evaluated to assess the existence of an association with the TST results (Table 4). The only variable analyzed that resulted in a significant association was contact with a TB patient ( $\mathrm{p} \leq 0.05)$, as evidenced by the greater proportion of positive results among patients who reported contact with a person with $\mathrm{TB}$. The risk ratio for having LTB among those who were previously exposed to TB was 8.44 $(95 \% \mathrm{CI}=4.97-14.35)$. Therefore, among the individuals who had contact with persons with active TB, LTB was 8.5 times more prevalent than in those who did not have contact.

More deaths were observed among the patients with positive TST results than among those with negative results; however, the causes of death were not related to the development of active TB.

The etiologies of CKD and the evaluated comorbidities, which are presented in Table 5, showed that patients with hypertension and glomerulonephritis, whether separately or together, did not have positive TST results. In contrast, patients with uropathies (18.8\%) did have positive TST results.

The most common professions or occupations were housekeeper $(14.6 \%)$, driver $(6.7 \%)$, farmer $(5 \%)$, mason $(4.5 \%)$, merchant $(3.8 \%)$, general services and salesman $(3.6 \%)$, and other (53.1\%).

The most commonly used medications were vitamin and mineral supplements (353), anti-platelets and antianginals (337), antihypertensives and cardiotonics (332), phosphate binders (234), antianemics (219), antacids (64), and insulin (60).

Upon chest radiography, 39 patients $(90.7 \%)$ showed no changes, whereas 4 patients presented with radiographic changes and underwent thorax tomography and bronchoscopy.

TABLE 1 - Results regarding the number of patients with CKD and positive TST results obtained from the hemodialysis services of Campo Grande, State of Mato Grosso do Sul, Brazil, in 2013.

\begin{tabular}{lcc}
\hline Hemodialysis services & Sample & Positive TST result \\
\hline University Hospital (number of patients: 30) & 26 & 5 \\
Regional Hospital of Mato Grosso do Sul (number of patients: 40) & 31 & 4 \\
Clinical Hiperrim (number of patients: 230) & 106 & 106 \\
Integrated Medical Services In Nephrology (number of patients: 229) & 62 & 11 \\
Institute of Kidney Diseases (number of patients: 88) & 87 & 7 \\
Pró-Renal - Clinic Kidney Diseases (number of patients: 155) & 418 & 63 \\
Total (number of patients: 772) & 43 \\
\hline
\end{tabular}

CKD: chronic kidney disease. TST: tuberculin skin test.

TABLE 2 - Prevalence of individuals with TB in the districts of Campo Grande, according to latent tuberculosis in hemodialysis services, of Campo Grande, State of Mato Grosso do Sul, Brazil, 2013.

\begin{tabular}{|c|c|c|c|c|c|}
\hline District & Population & TB disease & \multicolumn{2}{|c|}{ Patients with CKD } & TB latent \\
\hline North & 154,063 & 149 & 78 & 25.2 & 11 \\
\hline East & 129,312 & 33 & 53 & 15.5 & 5 \\
\hline West & 228,525 & 61 & 83 & 24.4 & 8 \\
\hline
\end{tabular}

TB: tuberculosis; CKD: chronic kidney disease. 
TABLE 3 - Epidemiological characteristics of the CKD patients, according to the TST results obtained from the hemodialysis services of Campo Grande, State of Mato Grosso do Sul, Brazil, in 2013.

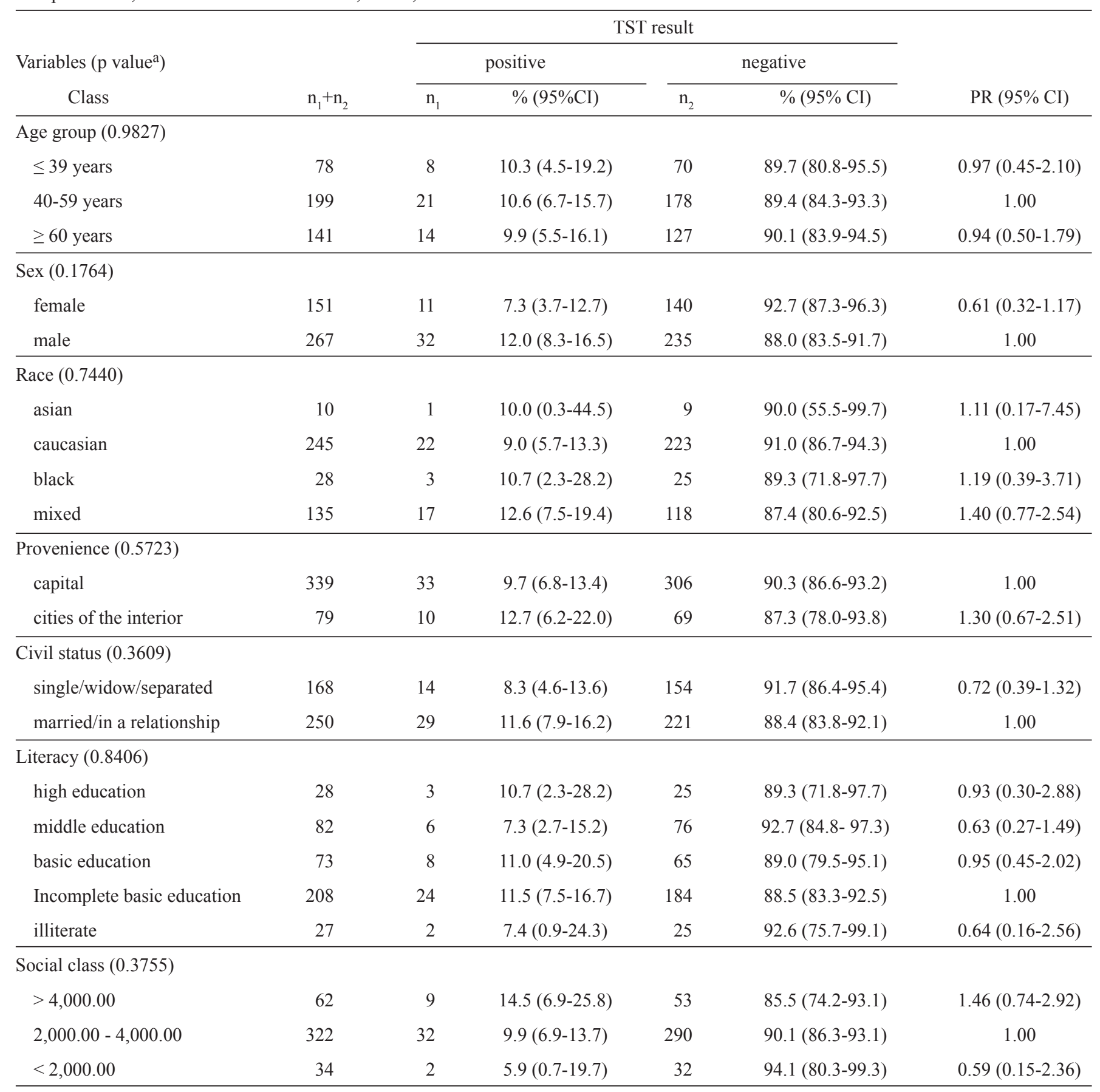

CKD: chronic kidney disease; TST: tuberculin skin test; 95\%CI: 95\% confidence interval; PR: prevalence ratio; ${ }^{\mathrm{a}} \mathrm{p}$-value from the chi-squared test or Fisher's exact test.

None of the patients were diagnosed with active TB after TST, and none presented with respiratory symptoms.

One patient, who was in the fourth month of treatment for LTB, underwent kidney transplantation and developed symptoms of weight loss, low-grade fever, and pleural effusion, which were diagnosed by the medical team as extrapulmonary TB. After beginning TB treatment, the patient's clinical condition significantly improved.
Adherence to LTB treatment with isoniazid was $97.7 \%$. After 4 days of treatment, two patients developed psychosis, making it necessary to discontinue the medication and replace isoniazid with another drug, rifampin. Three patients had adverse reactions to epigastralgia, although these reactions did not prevent the use of isoniazid. 
TABLE 4 - Clinical characteristics of the CKD patients, according to the TST results obtained from the hemodialysis services of Campo Grande, State of Mato Grosso do Sul, Brazil, in 2013.

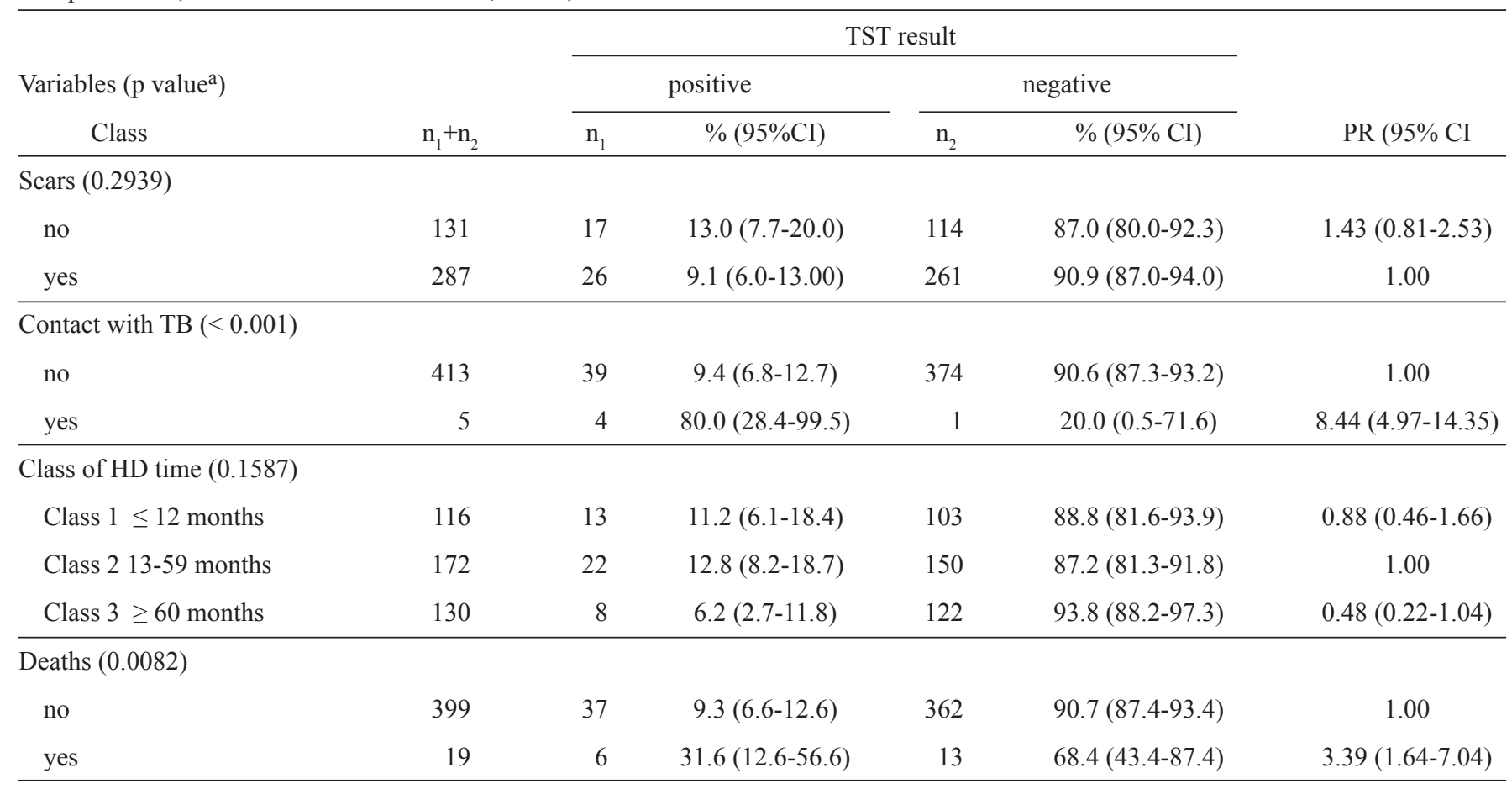

CKD: chronic kidney disease; TST: tuberculin skin test; 95\%CI: confidence interval; PR: prevalence ratio; HD: hemodialysis. ${ }^{\mathrm{a}} \mathrm{p}$-value from the chi-squared test or Fisher's exact test.

TABLE 5 - Disease distribution among the CKD patients, according to the TST results obtained from the hemodialysis services of Campo Grande, State of Mato Grosso do Sul, Brazil, in 2013.

\begin{tabular}{|c|c|c|c|c|c|}
\hline \multirow[b]{2}{*}{ Diseases } & \multicolumn{4}{|c|}{ TST result } & \multirow[b]{2}{*}{ Total } \\
\hline & $\mathrm{n}$ & $\%$ & $\mathrm{n}$ & $\%$ & \\
\hline Hypertension & 27 & 13.9 & 167 & 86.1 & 194 \\
\hline Hypertension and diabetes & 7 & 7.9 & 82 & 92.1 & 89 \\
\hline Glomerulonephritis & 0 & 0.0 & 19 & 100.0 & 19 \\
\hline Uropathies & 3 & 18.8 & 13 & 81.3 & 16 \\
\hline Hypertension and others & 1 & 7.1 & 13 & 92.9 & 14 \\
\hline Hypertension and glomerulonephritis & 0 & 0.0 & 12 & 100.0 & 12 \\
\hline
\end{tabular}

CKD: chronic kidney disease; TST: tuberculin skin test.

\section{DISCUSSION}

This study demonstrated that the incidence of LTB was low in chronic renal failure patients who were undergoing hemodialysis. Previous contact with individuals with active TB was significantly associated with latent infection.
Note that one-third of the world's population has an M. tuberculosis infection ${ }^{23}$. For effective TB control, it is important to identify and to treat active and latent TB cases ${ }^{9,28}$.

Chronic renal failure patients who are undergoing hemodialysis are approximately 10 times more likely to develop TB than the general population ${ }^{30}$. The greatest risk for developing the disease occurs two years after being infected with M. tuberculosis ${ }^{31,32}$. 
In Brazil, TST is the classic diagnostic tool for LTB. It is essential to perform the TST on an admitted chronic renal failure patient attending a regular hemodialysis program ${ }^{33}$.

The prevalence of LTB in this study was $10.3 \%$, which is similar to that observed in a cohort study conducted in India $(10.5 \%)^{34}$. These results, however, disagree with the prevalences of $15 \%$ from studies in Belgium ${ }^{35}$ and $20 \%$ from studies in Berlin $^{36}$.

The LTB prevalence detected in this study also differs from that obtained in Minas Gerais, in which the value was $28.5 \%^{37}$, and in Turkey, in a study by Ates et al., in which the prevalence was $37.5 \%{ }^{38}$. We emphasize that this variation may be related to the burden of TB in each region. Although Brazil is classified as a country with a high TB burden, the State of Mato Grosso do Sul only has a moderate burden of the disease, with an incidence rate of 37.7 cases per 100,000 inhabitants ${ }^{1,39}$.

Concerning the demographic characterization of the sample, the results regarding sex and marital status were similar to those obtained in the studies conducted by Fonseca et al. ${ }^{37}$ and Rao et al. ${ }^{40}$.

There was no significant association between the presence of LTB and the measured variables (i.e., age, gender, ethnicity, origin marital education class, BCG vaccination scar, and hemodialysis duration). These results align with those in the study performed in Turkey by Ates et al. ${ }^{38}$ and with the study of Ribeiro et al. ${ }^{41}$, which took place in the interior of São Paulo and included study subjects that had been on hemodialysis for at least three years.

Among the underlying causes of chronic renal failure, hypertension, diabetes mellitus, and glomerulonephritis were dominant. In the case of the latter, when assessed separately in this study, none of the patients had a positive TST result. The prevalence of these diseases was also detailed in the studies performed in Brazil by Cherchiglia et al. ${ }^{8}$ and Sesso et $\mathrm{al}^{42}$.

We observed that the most common medications used were vitamins and minerals, antianginals and antiplatelets, antihypertensives, and cardiotonic supplements. These findings differ from those in a study that found erythropoietin, intravenous iron, vitamin $\mathrm{D}$, and sevelamer were the predominant medications used ${ }^{42}$. We believe that these differences may be explained by the different pathological and clinical conditions presented by the patients.

In this study, previous contact with patients with active TB was significantly associated with latent infection. This result was supported by studies that reported that prior contact with an active TB patient is required for the development of latent infection ${ }^{12,36}$. A significant percentage of cases of active TB is usually due to the reactivation of LTB, which reinforces the need to limit contacts with patients with active TB in the community. The frequency of previous contact with TB patients was a key finding in this study; $80 \%$ of the patients with LTB reported such contact. This result differs from those obtained by Fonseca et al. ${ }^{37}$, whose research showed a rate of $20.6 \%$.
This rate may be biased by the patients' lack of clarity regarding what constituted contact.

The treatment of TBL is a preventive measure aimed at reducing the risk of progression among the large group of infected individuals for TB ativa ${ }^{2,43,44}$. Other studies have reported that supervised treatment is one of the main tools for TB treatment adherence ${ }^{45,46}$.

Treatment adherence in this study reached $97.7 \%$, which was greater than the adherence rates reported in other studies (e.g., $87.7 \%$ and $44 \%)^{47,48}$.

Positive adherence was obtained in the present study. We built on the strategies recommended by the Tuberculosis Control Program regarding the employment of capable human resources and the effective distribution of medications. These strategies include the choice of medications, regimen, and treatment duration, as well as determining patient needs and motivations to stay in treatment ${ }^{2}$.

Many strategies have been proposed ${ }^{2}$. The treatment in this study was self-administered, with monthly delivery of medication by the researcher. The participants were followed up in their respective dialysis clinics and counseled regarding the importance of treatment adherence and adverse reactions. Many of these patients spent much time on dialysis and, thus, experienced financial and mobility difficulties. We believe that these measures and systematic visits contributed to effective treatment adherence and may have hindered further shifting to and searching for other services to treat LTB.

A study of treatment cessation in users of health services in Recife highlighted the importance of having a health provider with whom the patient has close ties. This relationship is essential to the success of treatment adherence, as it facilitates the negotiation of the proposed actions with the user and the consequent care management ${ }^{49}$.

In Mato Grosso do Sul, the present study was the first to investigate the prevalence of LTB in chronic renal failure patients who were undergoing hemodialysis. To reduce the risk of developing active TB and, therefore, favor treatment that reduces the risk from $90 \%$ to $60 \%$, it is essential that health services adopt protocols to detect LTB, particularly for patients who are awaiting transplantation ${ }^{43,50}$.

In this study, we demonstrated that the prevalence of LTB in chronic renal failure patients who were undergoing hemodialysis was $10.29 \%$ and that previous contact with individuals with active TB was associated with the occurrence of latent infection. Treatment adherence was high, and the strategy of having patients self-administer drugs combined with systematic patient monitoring by a researcher in the hemodialysis unit might have contributed to the high treatment adherence in this study. Therefore, we suggest the adoption of this strategy in other health service areas that require preventive LTB treatment.

\section{CONFLICT OF INTEREST}

The authors declare that there is no conflict of interest. 


\section{REFERENCES}

1. World Health Organization (WHO). Global Tuberculosis Report 2013. Genebra, Suíça: WHO Library; 2013.

2. Ministério da Saúde. Secretaria de Vigilância em Saúde. Departamento de Vigilância Epidemiológica. Manual de recomendações para o controle da tuberculose no Brasil. Série A. Normas e Manuais Técnicos. Brasília: Ministério da Saúde; 2011.

3. Hino P, Cunha TN, Villa TCS, Santos CB. Perfil dos casos novos de tuberculose notificados em Ribeirão Preto (SP) no período de 2000 a 2006. Ciênc Saúde Coletiva 2011; 16 (supl I):1295-1301.

4. Arcêncio R, Oliveira MF, Villa TCS. Internações por tuberculose pulmonar no Estado de São Paulo no ano de 2004. Cienc Saude Coletiva 2007; 12:409-417.

5. Ministério da Saúde. Secretaria de Vigilância em Saúde. Boletim Epidemiológico. Brasília: MS 2013; p. 1-12.

6. Collins AJ, Foley RN, Herzog C, Chavers B, Gilbertson D, Ishani A, et al. US renal data system 2010 annual data report. Am J Kidney Dis 2011; 57:A8.

7. Milburn H, Ashman N, Davies P, Doffman S, Drobniewski F, Khoo S, et al. Guidelines for the prevention and management of Mycobacterium tuberculosis infection and disease in adult patients with chronic kidney disease. Thorax 2010; 65:559-570.

8. Cherchiglia ML, Machado EL, Szuster DAC, Andrade EIG, Acúrcio FA, Caiaffa WT, et al. Perfil epidemiológico dos pacientes em terapia renal substitutiva no Brasil, 2000-2004. Rev Saude Publica 2010; 44:4.

9. Sociedade Brasileira de Nefrologia (SBN) [Internet]. [Cited 20 Nov 2012]. Available at: http://www.sbn.org.br/leigos/index.php?insuficienci aRenal\&menu $=24 /$.

10. Narsipur SS, Madan A. Optimal tuberculosis screening of hemodialysis patients. Nephron 1999; 82:356.

11. Unsal A, Ahbap E, Basturk T, Koc Y, Sakaci T, Arar AS, et al. Tuberculosis in dialysis patients: a nine-year retrospective analysis. J Infect Dev Ctries 2013; 7:208-213.

12. Barrios-Payán JA, Castañón-Arreola M, Flores-Valdez MA, HernándezPando R. Aspectos biológicos, clínicos y epidemiológicos de la tuberculosis latente: Biological, clinical and epidemiological aspects of latent tuberculosis. Salud Publica Mex 2010; 52:70-78.

13. Sester M, Sester U, Clauer P, Heine G, Mack U, Moll T, et al. Tuberculin skin testing underestimates a high prevalence of latent tuberculosis infection in hemodialysis patients. Kidney Int 2004; 65:1826-1834.

14. Belcon MC, Smith EK, Kahana LM, Shimizu AG: Tuberculosis in dialysis patients. Clin Nephrol 1982; 17:14-18.

15. Donnelly PK, Shenton BK, Alomran AM, Francis DM, Proud G, Taylor RM. A new mechanism of humoral immunodepression in chronic renal failure and its importance to dialysis and transplantation. Proc Eur Dial Transplant Assoc 1983; 20:297-304.

16. Chan TYK. Vitamin D deficiency and susceptibility to tuberculosis. Calcif Tissue Int 2000; 66:476-478.

17. Pradhan RP, Katz LA, Nidus BD, Matalon R, Eisinger RP. Tuberculosis in dialyzed patients. JAMA 1974; 229:798-800.

18. Hussein MM, Mooij JM, Roujouleh H. Tuberculosis and chronic renal disease. Semin Dial 2003; 16:38-44.

19. Ahmed AT, Karter AJ. Tuberculosis in California dialysis patients. Int J Tuberc Lung Dis 2004; 8:341-345.

20. Chou KJ, Fang HC, Bai KJ, Hwang SJ, Yang WC, Chung HM. Tuberculosis in maintenance dialysis patients. Nephron 2001; 88:138-143.

21. Simon TA, Paul S, Wartenberg D, Tokars JI. Tuberculosis in hemodialysis patients in New Jersey: a statewide study. Infect Control Hosp Epidemiol 1999; 20:607-609.

22. Chia S, Karim M, Elwood RK, FitzGerald JM. Risk of tuberculosis in dialysis patients: a population-based study. Int J Tuberc Lung Dis 1998; 2:989-991.
23. Piller RVB. Epidemiologia da Tuberculose. Pulmão 2012; 121:4-9.

24. Dobler CC, McDonald SP, Marks GB. Risk of tuberculosis in dialysis patients: a nationwide cohort study. PLoS ONE 2011; 6:e29563.

25. Zar JH. Bioestatistical Analisys. $2^{\text {nd }}$ ed. New Jersey: Prince Hall; 1984.

26. Comissão de Tuberculose da SBPT, Grupo de Trabalho das Diretrizes para Tuberculose da SBPT. III Diretrizes para Tuberculose da Sociedade Brasileira de Pneumologia e Tisiologia (SBPT). J Bras Pneumol 2009; 35:1018-1048.

27. Statistical Analyses System (SAS). SAS/STAT user's guide: statistics, version 9.1. Cary, NC: SAS Institute; 2004.

28. Centers for Disease Control and Prevention (CDC). Essential components of a tuberculosis prevention and control program, and screening for tuberculosis and tuberculosis infection in high-risk populations: recommendations of the Advisory Council for the Elimination of Tuberculosis. MMWR 1995; 44(RR-11):2.

29. Grupo de Trabajo de Tuberculosis de las Sociedades Científicas, Comunidades Autónomas, Ministerio de Sanidad, Consumo, Plan para la prevención y control de la tuberculosis en España. Arch Bronconeumol 2009; 45:139-144.

30. Richardson RMA. The Diagnosis of Tuberculosis in Dialysis Patients. Semin Dial 2012; 25:419-422.

31. Morán-Mendoza, Marion SA, Elwood K, Patrick DM, FitzGerald JM. Tuberculin skin test size and risk of tuberculosis development: a large population-based study in contacts. Int J Tuberc Lung Dis 2007; 11:1014-1020.

32. Millet JP, Moreno A, Fina L, del Bano L, Orcau A, Olalla PG, et al. Factors that influence current tuberculosis epidemiology. Eur Spine J 2013; 22:539-548.

33. Christopoulos AI. Risk factors for tuberculosis in dialysis patients: a prospective multi-center clinical trial. BMC Nephrology 2009; 10:36.

34. Agarwal SK, Gupta S, Bhowmik D, Mahajan S. Tuberculin skin test for the diagnosis of latent tuberculosis during renal replacement therapy in an endemic area: a single center study. Indian J Nephrol 2010; 3:132-136

35. Wauters A. The value of tuberculin skin testing in haemodialysis patients. Nephrol Dial Transplant 2004; 19:433-438.

36. Pilsczek FH, Kaufmann SHE. Prevalence and predictors of positive tuberculin skin test results in a research laboratory. Rev Soc Bras Med Trop 2008; 41:416-418.

37. Fonseca JC, Caiaffa WT, Abreu MNS, Farah KP, Carvalho WS, Miranda SS. Prevalência de infecção latente por Mycobacterium tuberculosis e risco de infecção em pacientes com insuficiência renal crônica em hemodiálise em um centro de referência no Brasil. J Bras Pneumol 2013; 39:2.

38. Ates G, Yildiz T, Danis R, Akyildiz L, Erturk B, Beyazit H, et al. Incidence of Tuberculosis Disease and Latent Tuberculosis Infection in Patients with End Stage Renal Disease in an Endemic Region. Renal Failure 2010; 32:91-95

39. Ministério da Saúde. Secretaria de Vigilância em Saúde. Boletim Epidemiológico 2012; 43:1-12

40. Rao T, Ram R, Swarnalatha G, Santhosh Pai B, Ramesh V, Rao C, et al. Tuberculosis in haemodialysis patients: A single centre experience. Indian J Nephrol 2013; 23:340-345.

41. Ribeiro RCHM, Oliveira GASA, Ribeiro DF, Bertolin DC, Cesarino CB, Lima LCEQ, et al. Caracterização e etiologia da insuficiência renal crônica em unidade de nefrologia do interior do Estado de São Paulo. Acta Paul Enferm 2008; 21:207-211.

42. Sesso RCC, Alberto LA, Saldanha TF, Ronaldo LJ, Yoshimi W, Rinaldi SD. Diálise Crônica no Brasil - Relatório do Censo Brasileiro de Diálise, 2011. J Bras Nefrol 2012; 34:272-277.

43. Centers for Disease Control and Prevention (CDC). Targeted tuberculin testing and treatment of latent tuberculosis infection. MMWR Morb Mortal Wkly Rep 2000; 49(RR-6):1-51.

44. The Canadian Lung Association (CLA), Canadian Thoracic Society (CTS), Public Health Agency of Canada (PHAC). Canadian tuberculosis standards. $6^{\text {th }}$ ed. Ottawa (ON): CLA/CTS/PHAC; 2007. 
45. Silva ACO, Sousa MCM, Nogueira JA, Motta MCS. Tratamento supervisionado no controle da tuberculose: potencialidades e fragilidades na percepção do enfermeiro. Rev Eletrônica Enferm 2007; 9:402-416.

46. Paz LNF, Ohnishi MDO, Barbagelata CM, Bastos FA, Oliveira III JAF, Parente IC. Efetividade do tratamento da tuberculose. J Bras Pneumol 2012; 38:503-510.

47. Souza CTV, Hökerberg YHM, Pacheco SJB, Rolla VC, Passos SRL. Effectiveness and safety of isoniazid chemoprophylaxis for HIV-1 infected patients from Rio de Janeiro. Mem Inst Oswaldo Cruz 2009; 104:462-467.
48. Li J, Munsiff S, Tarantino T, Dorsinville M. Adherence to treatment of latent tuberculosis infection in a clinical population in New York City. Int J Infect Dis 2010; 14:292-297.

49. Oliveira JF, Antunes MBC. Abandono anunciado ao tratamento da tuberculose em uma unidade de saúde da família do recife - a perspectiva do usuário. Rev APS 2012; 15:4-13.

50. Reichler MR, Reves R, Bur S, Thompson V, Mangura BT, Ford J, et al. Evaluation of investigations conducted to detect and prevent transmission of tuberculosis. JAMA 2002; 287:991-995. 